\title{
How useful is visual field testing in an African glaucoma clinic?
}

\author{
This article was published in the following Dove Press journal: \\ Clinical Ophthalmology \\ 9 September 2014 \\ Number of times this article has been viewed
}

\author{
Mpopi Lenake ${ }^{1,2}$ \\ Colin Cook ${ }^{1,2}$ \\ Hamzah Mustak ${ }^{1,2}$ \\ Nagib Du Toit ${ }^{1,2}$ \\ 'Division of Ophthalmology, \\ Department of Surgery, Groote \\ Schuur Hospital, Cape Town, \\ South Africa; ${ }^{2}$ The University of \\ Cape Town, Cape Town, South Africa
}

Correspondence: Mpopi Lenake Faculty of Health Sciences, H53 Old Main Building, Groote Schuur Hospital, Observatory, Cape Town, South Africa Email lenakem@gmail.com
Purpose: To investigate the usefulness of visual field testing in the diagnosis and subsequent management of glaucoma in a specialist glaucoma clinic at Groote Schuur Hospital, Cape Town, South Africa.

Methods: A retrospective case note review of 344 patients who attended the glaucoma clinic between January and June 2010.

Results: The study population consisted of 201 (58\%) females and 143 (42\%) males. The diagnoses included 207 (60\%) cases with primary open-angle glaucoma, $58(17 \%)$ cases with chronic angle closure glaucoma, 46 (13\%) cases with secondary glaucoma, 17 (5\%) cases with normal pressure glaucoma, ten (3\%) cases with ocular hypertension, and six (2\%) glaucoma suspects. Visual field testing contributed to the diagnosis of glaucoma in only $34(10 \%)$ cases. A total number of 2,604 fields were performed. Of these fields, 1,931 (74\%) were reliable. A baseline was reached in only 141 (53\%) patients. There was evidence of field progression in only $24(9 \%)$ cases. Changes to glaucoma treatment were based on inadequate control of intraocular pressure alone in $309(90 \%)$ patients. Visual field progression contributed to changes in treatment in only $15(4 \%)$ cases.

Conclusion: Visual fields are not used in the diagnosis and management of glaucoma in the majority of patients in our clinic. Patients present with advanced disease, which is easily diagnosed without the use of visual fields. Progression of fields seldom contributes to monitoring and intraocular pressure is mainly used to monitor the adequacy of treatment.

Keywords: Humphrey visual fields, reliability, diagnosis, progression

\section{Introduction}

In Africa, $15 \%$ of blindness is due to glaucoma and it is also the region with the highest prevalence of blindness relative to other regions worldwide. ${ }^{1}$ Socioeconomic deprivation, poor access to health care, and suboptimal diagnosis and management are contributing factors and this often leads to late presentation. Due to difficulties previously encountered in case detection and uncertainties about how to manage the disease in a blindness prevention program, it was not included as a priority disease in the first phase of Vision 2020 planning for Africa. Vision 2020 is the global initiative for the elimination of avoidable blindness, a joint program of the World Health Organization (WHO) and the International Agency for the Prevention of Blindness (IAPB). ${ }^{2}$

Automated perimetry has been established as the standard method of testing by which patients at risk for glaucoma and those with documented field loss are followed in research studies and in clinical practice. There are a number of visual field analyzers available on the market, but many landmark clinical studies utilized the Humphrey Field Analyzer (Carl Zeiss Meditec AG, Jena, Germany) to assist with glaucoma diagnosis and progression. ${ }^{3-7}$ 
Many eye units in Africa are not equipped with visual field analyzers and there have been no reports of the contribution of visual fields to glaucoma management in those centers that do have the equipment. The use of visual field analyzers has been recommended for glaucoma management in African clinics, specifically to assist in screening, diagnosis, and monitoring of progression as part of the Vision 2020 program.

The eye clinic at Groote Schuur Hospital is a tertiary-level referral center that treats patients with primary, secondary, and tertiary eye diseases. The clinic is equipped with two Humphrey visual field II-i-series analyzers, which have been in use for approximately 15 years. Other tools available in this unit to assist with the management of glaucoma are disc photography and Goldmann applanation tonometry.

Therefore, the aim of this study was to determine the contribution of Humphrey visual field testing to the management of glaucoma cases in our specialist glaucoma clinic.

\section{Materials and methods}

We conducted a retrospective, consecutive case note review of 446 patients attending the glaucoma clinic for the 6 months between January and June 2010. Ethical approval was obtained from the Research Ethics Committee of the Faculty of Health Sciences, University of Cape Town (Cape Town, South Africa). The diagnosis of glaucoma was based on the findings noted by the clinician in the clinical notes, namely disc findings in keeping with glaucoma - a vertical cup-to-disc ratio of 0.7 or more \pm raised intraocular pressure \pm a visual field defect suggestive of glaucoma. Visual field reliability was defined as per the manufacturer's guidelines for standard threshold testing: less than $20 \%$ fixation losses or less than $33 \%$ false-negative responses or less than 33\% false-positive responses. A visual field was indicative of glaucoma if the hemifield test was outside normal limits and there was a cluster of three contiguous points at the $5 \%$ level on the pattern deviation plot. Baseline was defined as two early, similar, reliable fields. Visual field progression was defined as deterioration of three or more points at the same location at the $P<0.05$ level on three consecutive visual fields. Data was captured on an Excel spreadsheet and then analyzed using STATA (v10.0).

\section{Results}

Of the 446 case notes reviewed, 344 patients had performed Humphrey visual fields at some stage during their attendance at the clinic. Table 1 provides a summary of the sex and diagnosis groups of the subjects. The median age
Table I Sex and diagnosis distributions of patients reviewed

\begin{tabular}{llll}
\hline Diagnosis & Male & Female & Total $(\%)$ \\
\hline POAG & 94 & 113 & $207(60)$ \\
CACG & 18 & 40 & $58(17)$ \\
NTG & 7 & 10 & $17(5)$ \\
OHT & 4 & 6 & $10(3)$ \\
Glaucoma suspect & 0 & 6 & $6(1.7)$ \\
Other & 19 & 26 & $45(13)$ \\
NVG & 1 & 0 & $1(0.3)$ \\
Total & 143 & $20 \mathrm{I}$ & $344(100)$ \\
\hline
\end{tabular}

Abbreviations: CACG, chronic angle closure glaucoma; POAG, primary open angle glaucoma; NTG, normal tension glaucoma; NVG, neovascular glaucoma; $\mathrm{OHT}$, ocular hypertension.

( \pm interquartile range) at diagnosis was $58( \pm 18)$ years (range 17-93 years). The visual field testing strategies that were used are presented in Table 2. The median number of field tests performed per patient was six (IQR \pm 8 ; range 1-32). Of the total 2,604 field tests performed, 1,931 (74.2\%) were found to be reliable and $725(28 \%)$ tests were unreliable based on analysis of a single parameter, ie, fixation losses alone, false-negatives alone, or false-positives alone. The most common reason for unreliability was fixation losses (60\%), followed by false-negative responses (34\%), and false-positive responses (6\%). Table 3 provides the criteria used by clinicians to diagnose glaucoma. Ninety-four subjects were not included in this subanalysis -57 subjects were diagnosed elsewhere, 21 subjects were diagnosed before Humphrey visual fields were in use in the clinic, and 16 had ocular hypertension or were glaucoma suspects. Optic disc cupping with raised intraocular pressure was used more than any other criteria to diagnose glaucoma. This was statistically significant $(P<0.005)$. The median time between diagnosis of glaucoma and the first visual field test was 5.6 weeks. Eighty patients were excluded in the assessments of the baseline and evidence of progression because they had only performed one field test. The number of subjects reaching baseline was 141 (53.4\%). The number of subjects showing evidence of visual field progression was 24 (9\%). Treatment changes were based on a number of factors as presented in Table 4 . In $90 \%$ of subjects, the decision to change treatment was based on inadequate intraocular pressure control alone. This was statistically significant $(P<0.005)$.

Table 2 Visual field testing strategy used

\begin{tabular}{ll}
\hline Testing strategy & Number (\%) \\
\hline SITA-fast 24-2 & $2,58 \mathrm{I}(99.1)$ \\
SITA-fast I0-2 & $4(0.2)$ \\
Fastpac & $16(0.6)$ \\
Full threshold & $3(0.1)$ \\
Total & $2,604(100)$ \\
\hline
\end{tabular}


Table 3 Criteria used by clinicians to diagnose glaucoma

\begin{tabular}{llllll}
\hline Criteria & Diagnosis & & & \\
\cline { 2 - 5 } & POAG & CACG & NTG & Secondary glaucoma \\
\hline Disc only & 9 & 1 & 11 & 0 & 21 \\
Disc + IOP & 125 & 36 & 2 & 27 & 190 \\
Disc + IOP + HVF loss & 21 & 6 & 0 & 4 & 31 \\
Disc + HVF loss & 0 & 0 & 2 & 0 & 2 \\
IOP + HVF loss & 0 & 0 & 0 & 4 & I \\
IOP only & $\mathrm{I}$ & 0 & 0 & 36 & 5 \\
Total & 156 & 43 & 15 & 250 \\
\hline
\end{tabular}

Abbreviations: CACG, chronic angle closure glaucoma; HVF, Humphrey visual field; IOP, intraocular pressure; NTG, normal tension glaucoma; POAG, primary open angle glaucoma.

\section{Discussion}

This is the first clinic-based study describing the contribution of Humphrey visual field testing to the management of glaucoma in Africa.

Our results may be summarized as follows: 1) the majority of visual fields performed in this patient population were reliable; 2) most patients with glaucoma are diagnosed without the use of visual field tests; 3 ) only half the patients reach a baseline; and 4) there was evidence of visual field progression in a minority of patients and this contributed to changes in management in only a small number of patients.

Various population-based surveys assessing the prevalence of glaucoma in Africa included automated perimetry as part of the assessment. ${ }^{8-12}$ However, only two of these used the Humphrey Field Analyzer. ${ }^{8} 12$ In all these studies, the majority of subjects were diagnosed based on advanced structural changes with unproven field loss.

We found that the SITA-fast testing strategy was the most commonly used testing strategy in our clinic. It has been reported to have excellent sensitivity and specificity for glaucomatous visual field loss and is much faster than the full threshold testing strategy. ${ }^{13,14}$ However, it has also been reported to have variable repeatability. ${ }^{14}$ For this reason, some authors do not recommend the use of SITA-fast for glaucoma follow-up, while others suggest that it can be used,

Table 4 Treatment changes

\begin{tabular}{ll}
\hline Treatment & Number (\%) \\
\hline Inadequate IOP control alone & $309(90)$ \\
VF progression + inadequate IOP control & $13(4)$ \\
VF progression alone & $2(0.6)$ \\
No treatment started & $5(1.4)$ \\
No treatment change & $15(4)$ \\
Total & $344(100)$ \\
\hline
\end{tabular}

Abbreviations: IOP, intraocular pressure; VF, visual field. provided that all subsequent fields are performed using the same strategy to allow for comparison. ${ }^{15}$

Current literature suggests that no consensus exists regarding the reliability criteria that should be used for the SITA testing strategy. The manufacturer recommends the following criteria for reliability when using the SITA testing strategy: less than $20 \%$ fixation losses and less than $15 \%$ false-positive errors. There is no limit displayed on the machine for false-negative errors with SITA testing, but the machine prints these errors out as a percentage. Bengtsson ${ }^{16}$ published a report on the reliability of SITA-standard testing, stating that the reliability of a visual field can be predicted by the amount of field loss alone and that reliability indices contributed very little in this regard. A study by Budenz et $\mathrm{a}^{17}$ comparing full threshold testing to SITA used the reliability criteria similar to those recommended by the manufacturer ( $<33 \%$ fixation losses, false-negative errors, and false-positive errors) and found that glaucomatous defects are measured shallower using the SITA algorithms but are approximately the same size and severity compared with full threshold measurements. We used the original guidelines recommended by the manufacturer: less than $20 \%$ fixation losses, less than $33 \%$ false-positive responses, and less than $33 \%$ false-negative responses.

Although the majority of Humphrey visual field tests performed were reliable, they assisted in the diagnosis of glaucoma in only $34(10 \%)$ subjects in this study group. Furthermore, the first visual field was performed after the diagnosis of glaucoma had already been made in over half of the subjects in this study. There was no difficulty in making the diagnosis of glaucoma in the majority of subjects as it was clinically evident in 190 (55\%) subjects - the intraocular pressure was high and disc changes in keeping with glaucoma were present.

In our study, fixation loss errors were the most common cause of unreliability. A similar finding was reported in 
earlier studies. Katz and Sommer ${ }^{18}$ initially reported unreliability rates of $45 \%$ in glaucomatous subjects and $30 \%$ in normal controls. Most test results were unreliable because they failed to meet the criterion for fixation losses. Katz et $\mathrm{al}^{19}$ found that $19 \%$ of normal subjects, $28 \%$ of those with ocular hypertension, and $37 \%$ of patients with glaucoma were unreliable on initial automated testing. Fixation losses were the prime reason for almost all the repeatedly unreliable tests. An analysis of reliability indices of an urban glaucoma population by Birt et $\mathrm{al}^{20}$ showed $59.9 \%$ overall reliability. The most common cause of unreliability was fixation loss $(39 \%)$, followed by false-negative errors $(9 \%)$, and falsepositive errors $(5 \%)$.

Several landmark glaucoma trials have discussed the importance of having baseline fields to be able to compare future fields for progression. ${ }^{5,6,21,22}$ In our study, baseline was reached in half the subjects and visual field progression was evident in only $10 \%$ of subjects who had performed two or more visual field tests. The lack of usefulness of visual field testing was further demonstrated by the fact that visual field progression contributed to changes in management in only $15(4.4 \%)$ subjects.

There were no reports found in the literature of similar studies performed in eye clinics elsewhere in the world.

The main limitation of this study is its retrospective nature. Retrospective case record reviews are restricted to the information available in the records. Furthermore, a number of subjects were excluded from the subgroup analyses for various reasons; however, we believe that the numbers remained large enough to provide reliable statistical analysis. Some may also argue that this was a biased sample as most glaucoma is managed in non-subspecialty clinics - patients referred to the subspecialty clinic already have the disease and are often those who have complex management issues. This patient population is most likely skewed to the severe end of the spectrum and probably represents the "worst of the worst" patients in our clinic, but all these patients, including those with advanced disease, presented initially to ophthalmologists working in general clinics and not to glaucoma specialists.

\section{Conclusion}

In our glaucoma clinic, Humphrey visual field testing makes little contribution to the management of the majority of glaucoma cases seen. Although our clinic is better equipped than many other clinics on the continent, a significant proportion of our patients still present with advanced disease, which is easily diagnosed without the use of visual fields. Progression of fields seldom contributes to monitoring, and intraocular pressure is mainly used to monitor the adequacy of treatment. Ocular hypertensives, glaucoma suspects, and those with early glaucoma are also seen in our clinic and they continue to benefit from visual field testing. We do not know if the findings from this study necessarily represent the status quo of visual field testing in other African centers, but populationbased surveys have also shown that the majority of glaucoma cases in Africa present with advanced structural disease, which can be diagnosed without a visual field. Further research should be carried out to determine the usefulness of visual field testing in other centers in Africa - this will assist in planning for future blindness prevention programs.

\section{Acknowledgments}

The authors would like to thank the division of Ophthalmology at Groote Schuur Hospital (Cape Town, South Africa) for permitting the study to take place. It was presented at Ophthalmic Society of South Africa (OSSA) annual meeting in Cape Town in March 2013.

\section{Disclosure}

The authors report no conflicts of interest in this work.

\section{References}

1. Reshnikoff S, Pascolini D, Etya'ale D, et al. Global data on visual impairment in the year 2002. Bull World Health Organ. 2004;82(11):844-851.

2. World Health Organization. Prevention of Blindness and deafness. Global Initiative for the elimination of avoidable blindness. Geneva, Switzerland: World Health Organization; 2000. Available from: http:// apps.who.int/iris/handle/10665/63748. Accessed August 19, 2014.

3. Kass MA, Heuer DK, Higginbotham EJ, et al. The Ocular Hypertension Treatment Study: a randomized trial determines that topical ocular hypotensive medication delays or prevents the onset of primary openangle glaucoma. Arch Ophthalmol. 2002;120(6):701-713.

4. Musch DC, Lichter PR, Guire KE, Standardi CL. The Collaborative Initial Glaucoma Treatment Study: study design, methods, and baseline characteristics of enrolled patients. Ophthalmology. 1999;106(4):653-662.

5. Leske MC, Heijl A, Hyman L, Bengtsson B. Early Manifest Glaucoma Trial: design and baseline data. Ophthalmology. 1999;106(11): 2144-2153.

6. Comparison of glaucomatous progression between untreated patients with normal-tension glaucoma and patients with therapeutically reduced intraocular pressures. Collaborative Normal-Tension Glaucoma Study Group. Am J Ophthalmol. 1998;126(4):487-497.

7. Advanced Glaucoma Intervention Study. 2. Visual field test scoring and reliability. Ophthalmology. 1994;101(8):1445-1455.

8. Salmon JF, Mermoud A, Ivey A, Swanevelder SA, Hoffman M. The prevalence of primary angle closure glaucoma and open angle glaucoma in Mamre, Western Cape, South Africa. Arch Ophthalmol. 1993;111(9): $1263-1269$.

9. Buhrmann RR, Quigley HA, Barron Y, West SK, Oliva MS, Mmbaga BB. Prevalence of glaucoma in a rural East African population. Invest Ophthalmol Vis Sci. 2000;41(1):40-48.

10. Rotchford AP, Johnson GJ. Glaucoma in Zulus, a population-based cross-sectional survey in a rural district in South Africa. Arch Ophthalmol. 2002;120(4):471-478. 
11. Rotchford AP, Kirwan JF, Muller MA, Johnson GJ, Roux P. Temba Glaucoma study: a population-based cross-sectional survey in urban South Africa. Ophthalmology. 2003;110(2):376-382.

12. Ashaye A, Ashaolu O, Komolafe O, et al. Prevalence and types of glaucoma among an indigenous African population in Southwestern Nigeria. Invest Ophthalmol Vis Sci. 2013;54(12):7410-7416.

13. Bengtsson B, Heijl A. SITA Fast, a new rapid perimetric threshold test. Description of methods and evaluation in patients with manifest and suspect glaucoma. Acta Ophthalmol Scand. 1998;76(4):431-437.

14. Budenz DL, Rhee P, Feuer J, McSoley J, Johnson CA, Anderson DR. Sensitivity and specificity of the Swedish interactive threshold algorithm for glaucomatous visual field defects. Ophthalmology. 2002;109(6): 1052-1058.

15. Sekhar CG, Naduvilath TJ, Lakkai M, et al. Sensitivity of Swedish interactive threshold algorithm compared with standard full threshold algorithm in Humphrey visual field testing. Ophthalmology. 2000;107(7): 1303-1308.

16. Bengtsson B. Reliability of computerized perimetric threshold tests as assessed by reliability indices and threshold reproducibility in patients with suspect and manifest glaucoma. Acta Ophthalmol Scand. 2000;78(5):518-522.
17. Budenz DL, Rhee P, Feuer WJ, McSoley J, Johnson CA, Anderson DR. Comparison of glaucomatous visual field defects using standard full threshold and Swedish interactive threshold algorithms. Arch Ophthalmol. 2002;120(9):1136-1141.

18. Katz J, Sommer A. Reliability indexes of automated perimetric tests. Arch Ophthalmol. 1988;106(9):1252-1254.

19. Katz J, Sommer A, Witt K. Reliability of visual field results over repeated testing. Ophthalmology. 1991;98(1):70-75.

20. Birt CM, Shin DH, Samudrala V, Hughes BA, Kim C, Lee D. Analysis of reliability indices from Humphrey visual field tests in an urban glaucoma population. Ophthalmology. 1997;104(7):1126-1130.

21. Heijl A, Leske MC, Bengtsson B, Bengtsson B, Hussein M; Early Manifest Glaucoma Trial Group. Measuring visual field progression in the Early Manifest Glaucoma Trial. Acta Ophthalmol Scand. 2003;81(3):286-293.

22. Musch DC, Gillespie BW, Lichter PR, Niziol LM, Janz NK; CIGTS Study Investigators. Visual field progression in the Collaborative Initial Glaucoma Treatment Study the impact of treatment and other baseline factors. Ophthalmology. 2009;116(2):200-207.
Clinical Ophthalmology

\section{Publish your work in this journal}

Clinical Ophthalmology is an international, peer-reviewed journa covering all subspecialties within ophthalmology. Key topics include: Optometry; Visual science; Pharmacology and drug therapy in eye diseases; Basic Sciences; Primary and Secondary eye care; Patien Safety and Quality of Care Improvements. This journal is indexed on

Submit your manuscript here: http://www.dovepress.com/clinical-ophthalmology-journal

\section{Dovepress}

PubMed Central and CAS, and is the official journal of The Society of Clinical Ophthalmology (SCO). The manuscript management system is completely online and includes a very quick and fair peer-review system, which is all easy to use. Visit http://www.dovepress.com/ testimonials.php to read real quotes from published authors. 